\title{
THE GRAPHIC CONFIGURATION OF APICAL DIASTOLIC MURMURS
}

\author{
BY \\ BERTRAND G. WELLS \\ From the Cardiological Department, St. Bartholomew's Hospital
}

Received June 5, 1951

It is generally accepted that a rumbling diastolic murmur at the apex may occur in left ventricular dilatation without abnormality of the mitral valve. The Austin Flint murmur may arise in this manner or may perhaps be caused by the backward displacement of the anterior mitral leaflet by the regurgitant bloodstream. Such murmurs are difficult to differentiate from the murmurs of mitral stenosis, and phonocardiography has hitherto been of little assistance.

Since the analysis by Rappaport and Sprague $(1941,1942)$ of the physical laws that govern auscultation and of the ideal requirements of the phonocardiograph it has become clear that the instruments previously used were highly unsatisfactory. The object of this paper has been to make a study of apical diastolic murmurs with the latest " logarithmic" phonocardiograph. This study has produced results that may well enable the differentiation to be made between the murmurs of left ventricular dilatation and of mitral stenosis. Since the features on which this differentiation is based can only be properly recorded when the frequency response of the phonocardiograph is "logarithmic" it is necessary briefly to review the problem of frequency response.

\section{The Frequency Response of PhonocardiographS}

Movements of the heart beat cause vibrations to be set up in the chest which are conducted to the chest wall. These vibrations range in frequency from 1 to 1000 cycles per second. Those from 1 to 20 cycles per second are not audible. They are often of considerable intensity and are responsible for the cardiac impulse. When all vibrations from 1 to 1000 cycles per second are recorded so that their height is directly proportional to their energy the instrument is said to have a linear frequency response (from 1 to 1000 cycles). The low frequency vibrations dominate a "linear" phonocardiogram in such a manner that if the tracing is only a few centimetres in height the heart sounds and murmurs cannot be identified. Such a tracing from the apex is nevertheless of great value as a reference tracing and is called the " apex cardiogram."

The human hearing mechanism is sensitive to vibrations of 1000 cycles per second, but the sensitivity falls off in a logarithmic manner as the frequency is reduced to 20 cycles per second. If the phonocardiograph is so constructed that the sensitivity is reduced over the frequency range in exactly the same manner then it is said to have a "logarithmic" frequency response. This tracing should reproduce heart sounds and murmurs with a visual configuration exactly similar to the auditory impression on auscultation. If a faint high pitched murmur is audible as in minimal aortic regurgitation it will be recorded on the tracing even though the latter may not be more than a few centimetres in height. The reason for this is that the low frequency vibrations of many thousand times the energy have been attenuated. If the logarithmic attenuation of the lower frequency vibrations were removed (so that the response is again linear) the tracing might reach the height of over a hundred metres. If the frequency response were intermediate between the logarithmic and linear the tracing would remain impracticably large. If the height of the tracing were reduced the $1 \mathrm{~mm}$. vibrations that were audible will become too small to be identified. 


\section{MeTHOD AND MATERIAL}

The introduction of a high quality logarithmic phonocardiograph has enabled even the faintest murmur of aortic regurgitation to be consistently recorded, and the technique and results have been reported by Wells et al. (1949). An identical technique was used in this study, and the instruments used were the Sanborn Tribeam * and Sanborn Stethocardiette phonocardiographs.

Since there has been extensive study of the lower frequency components of apical diastolic murmurs the tracings analysed were all logarithmic records, and attention was paid mainly to the high frequency features in these tracings since these were the features that had not been satisfactorily studied before.

This study consists of the analysis of one hundred logarithmic phonocardiograms showing significant apical diastolic vibrations not due to normal third or auricular sounds. Vibrations were considered " significant" if they showed a period of maximal or minimal intensity that was repeated in subsequent cardiac cycles. The third sound was considered normal if it started immediately before the apex of the R1 wave of the apex cardiogram, and had a duration of not more than 0.16 seconds. The auricular sound was considered to be such when the vibrations were of low frequency and started after the onset of the $P$ wave of the electrocardiogram. Tracings were excluded if the diastolic vibrations had a similar configuration to those recorded from the base and were apparently conducted from a basal diastolic murmur. Apart from these considerations the tracings were consecutive records from different patients.

It is clear that the composition of this material depends entirely on the patients selected for

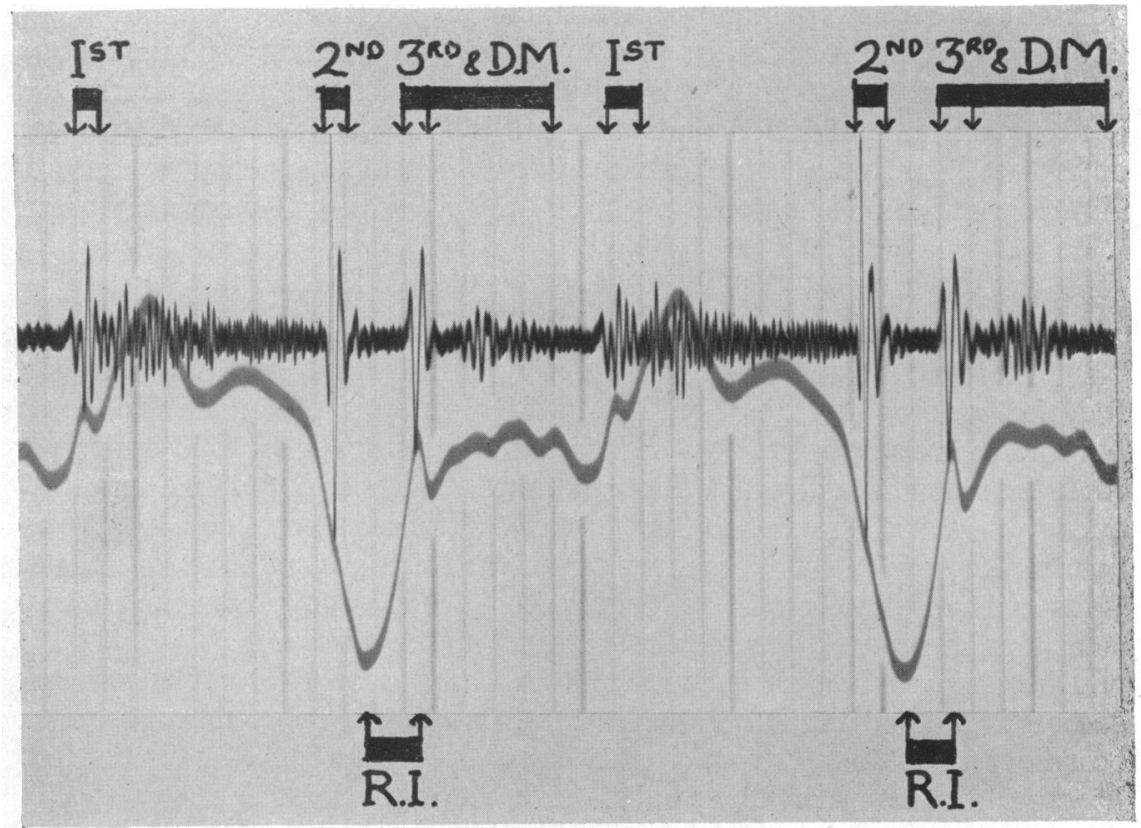

Fig. 1.-Synchronous phonocardiogram and apex cardiogram.

phonocardiography. In general tracings were taken whenever there was difference of opinion as to the auscultatory findings or their clinical significance, or from patients in whom there was cardiac dilatation with no audible murmur, to investigate the possible existence of inaudible vibrations. Comparatively few tracings were taken on patients with longstanding mitral stenosis and unequivocal physical signs. There is therefore only a small number of patients in whom

* Tracings taken when working on Ella Lyman Cabot Fellowship at Massachusetts General Hospital. 
an abnormal first sound and opening snap of the mitral valve were heard, for these signs are often present in well established mitral stenosis.

Since the tracings were selected because they showed significant diastolic vibrations there was not necessarily a diastolic murmur on auscultation. Indeed, 14 of the cases were considered on auscultation to have no diastolic murmur, and in a further 9 a diastolic murmur was considered questionable. In the remaining 77 cases the diastolic vibrations were considered to represent the diastolic murmur heard on auscultation.

\section{Configuration of Apical Diastolic Murmurs}

The onset of the diastolic vibrations constituting the murmur is characteristically at the time of the apex of the R1 wave of the apex cardiogram (Fig. 1). Between the second component of the second sound and the onset of the diastolic vibrations there is usually either complete silence (as in Fig. 1) or else a few high frequency vibrations attributed to the opening snap of the mitral valve (Fig. 2). The latter sound occurs at the time of onset of the R1 wave. In rare instances the diastolic vibrations commence at the time of opening of the A-V valves but increase markedly in amplitude at the time of the third sound. The vibrations that sometimes precede the A-V opening may be the third component of the second sound, vibrations transmitted from a basal diastolic murmur or part of a continuous mediastinal hum. They do not appear to be related to the apical diastolic vibrations under discussion.

The maximal intensity of the diastolic vibrations is just after the apex of the R1 wave of the apex cardiogram, and thereafter the vibrations show a continuous diminution in intensity and may become absent if diastole is prolonged (Fig. 2). In a few cases, however, the intensity of the vibrations appears relatively unchanged throughout diastole (Fig. 3).

In the 29 patients with auricular fibrillation or flutter a presystolic increase in the apical diastolic vibrations was never present nor was a presystolic murmur audible in these patients. In the 71 patients with sinus rhythm a presystolic increase in the vibrations was present in 34 although a presystolic murmur was recognized on auscultation in only half this number. In only one patient were there presystolic vibrations on the tracing without significant vibrations earlier in diastole.

Among the 37 patients. with no presystolic increase in vibrations a presystolic murmur was believed to be present in 7 . Alimurung et al. (1949) have recently discussed the reason for this

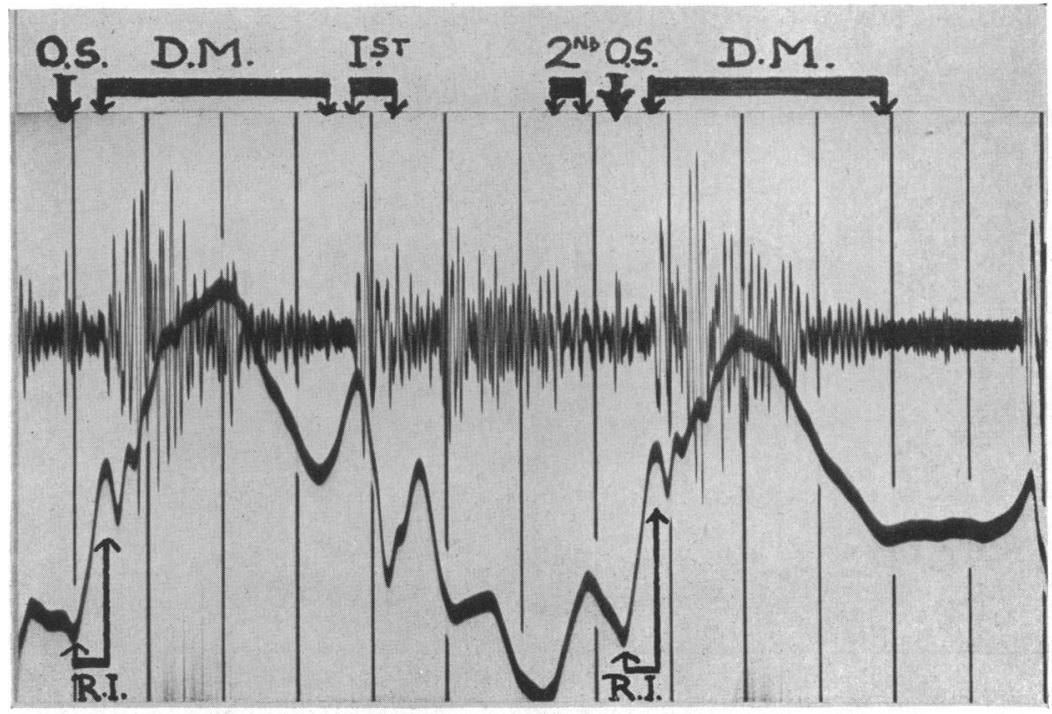

FIG. 2.-Upper tracing phonocardiogram. Lower tracing apex cardiogram. 
auscultatory impression and point out that a crescendo configuration of the first heart sound causes the auditory illusion. This explanation did not seem to apply to two of the present series but the remaining five showed a pronounced crescendo configuration of the first sound (Fig. 4). It seems probable that this illusion may explain how a presystolic murmur is sometimes believed to be present in cases of auricular fibrillation. An alternative situation in which a presystolic murmur is believed present is illustrated in Fig. 5. Here the interpretation is that there is a loud systolic gallop simulating an abnormal first heart sound. The normal first sound preceding the gallop was responsible for the auditory impression of a presystolic murmur. The true presystolic murmur starts before the onset of the QRS of the electrocardiogram (Fig. 6), and may occur in the absense of a systolic murmur.

The significance of apical diastolic vibrations appears, however, to be dependent less on their configuration than on the appearance of the first heart sound and the opening snap which will now be discussed.

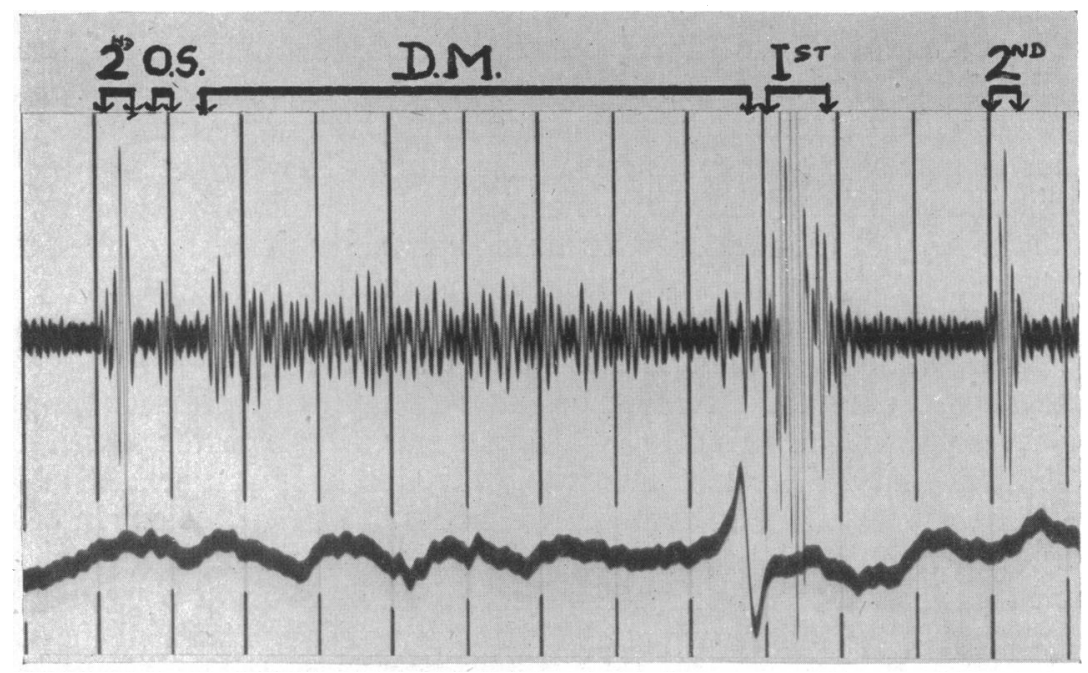

FIG. 3.-Phonocardiogram of patient with mitral stenosis and auricular fibrillation showing a diastolic murmur of fairly constant intensity.

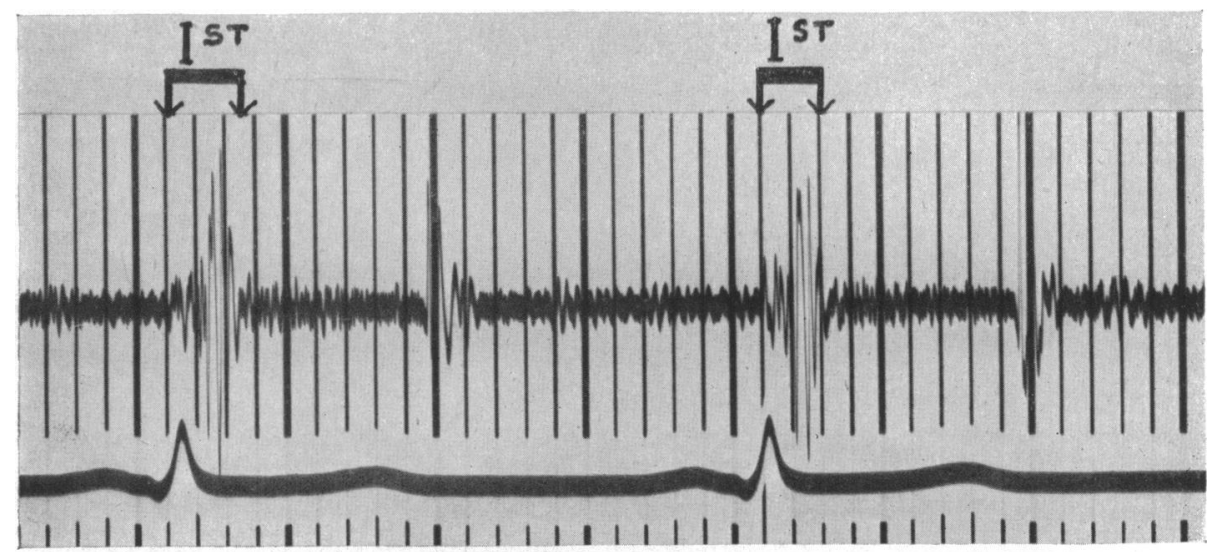

Fig. 4.-Crescendo first heart sound without presystolic murmur. A presystolic murmur had been diagnosed on auscultation. 


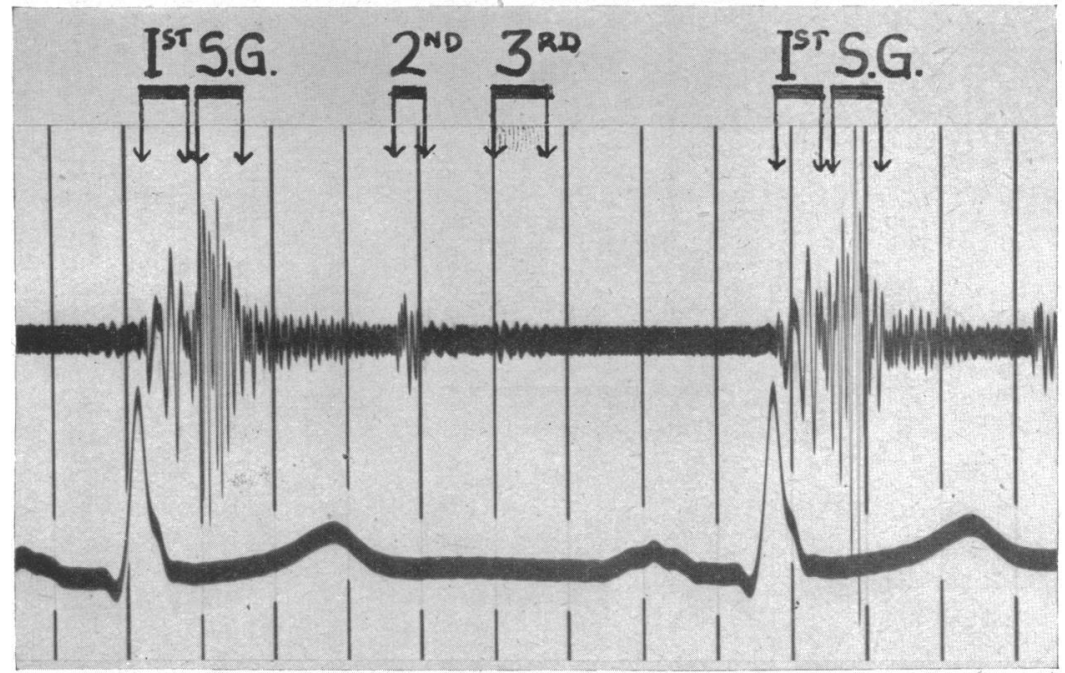

Fig. 5.-Normal first sound followed by a loud early systolic " gallop." This combination sounded on auscultation like an abnormal first sound preceded by a presystolic murmur.

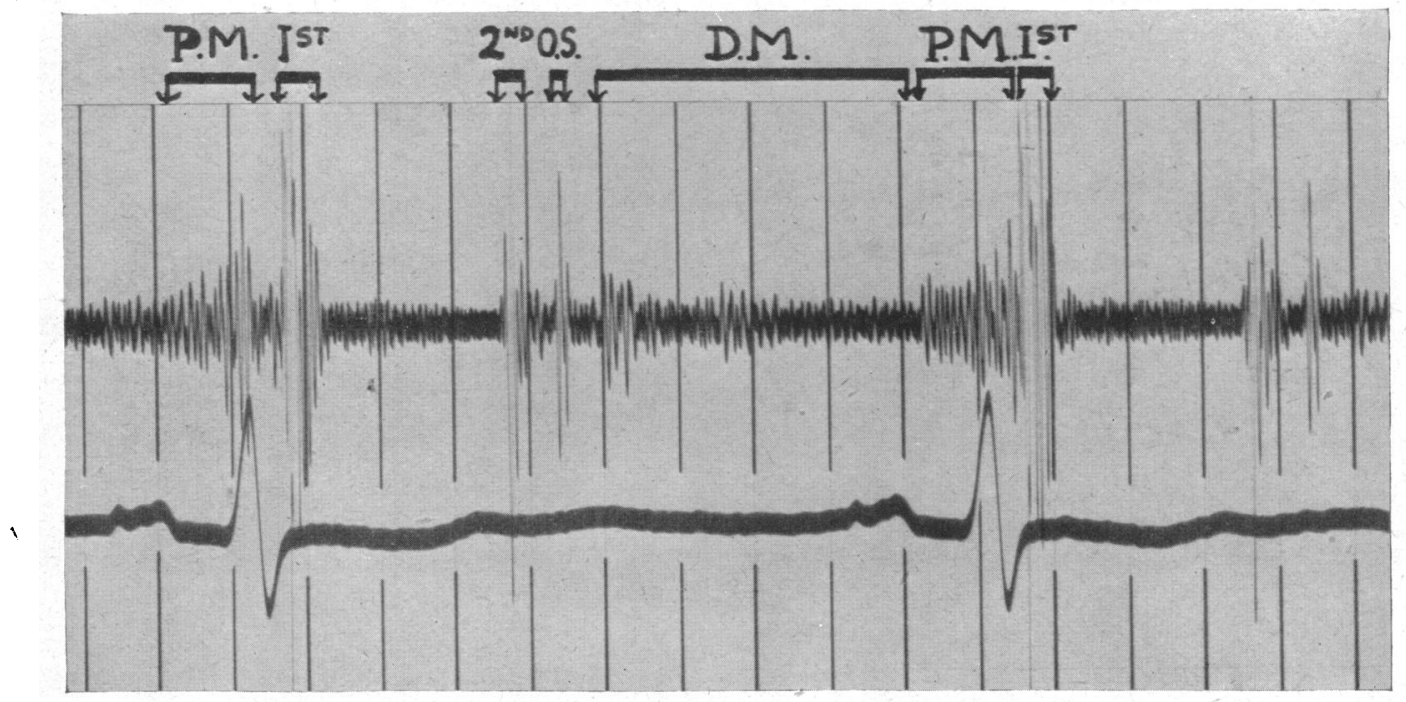

Fig. 6.-Typical presystolic murmur. Note the presystolic vibrations start before the onset of the QRS complex although the $P-R$ interval is only 0.15 sec.

\section{First Heart Sound and Vibrations of A-V Opening}

Accentuation of the first heart sound on auscultation is often characteristic of mitral stenosis. The sound is usually also of higher pitch than normal. There are, however, many cases of longstanding mitral stenosis in which the first heart sound is of low intensity or masked by being followed immediately by a systolic murmur. The present study indicates that the first sound may nevertheless be abnormal on the phonocardiogram. The abnormality consists of unusual delay in the onset of the maximal vibrations of the first sound; it was first discussed by Cossio and Berconsky (1943). We have found this feature more significant than abnormality of frequency 
or intensity of the sound. Although the electrocardiogram is considered unsuitable as a guide to mechanical events in the cardiac cycle it is probably sufficiently accurate to determine whether or not the first sound is abnormally late. We have considered that the maximal vibrations of the first sound should normally start within $0.06 \mathrm{sec}$. of the onset of the QRS, and that if they

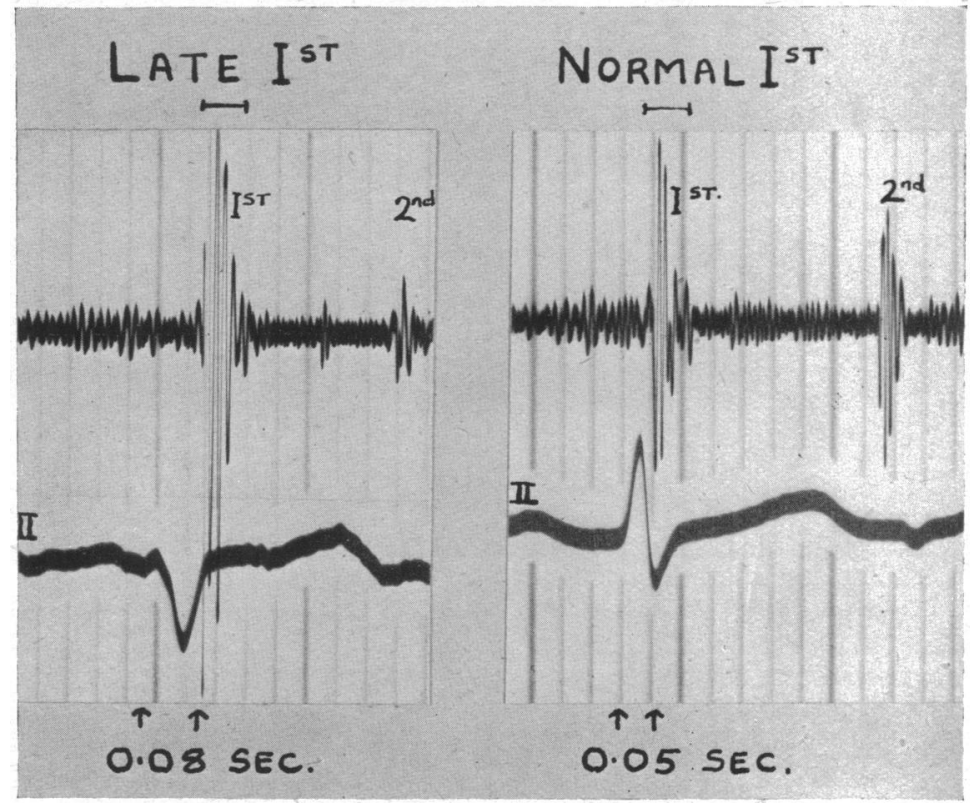

FIG. 7. - On the left is a "late" first sound occurring 0.08 secs. after the onset of the QRS. On the right is a normal first heart sound occurring less than 0.06 secs. after the onset of the QRS.

occur at $0.07 \mathrm{sec}$. or more the sound should be classified as " late" (Fig. 7). The first sound was late in 51 tracings of the present series and in 44 of these the maximal vibrations of the first sound were delayed enough to occur at or after the termination of the QRS complex. Of the 51 cases with late first sounds there were only 23 in which the first sound had been thought abnormal on auscultation, while in 4 of those with a normal first sound on the tracings it had been thought abnormal on auscultation.

Vibrations of $A-V$ Opening. The tracings were considered to show vibrations due to opening of the mitral valve when there were high frequency vibrations occurring at the time of onset of the R1 wave on the apex cardiogram (Fig. 2). An opening snap is often audible in established mitral stenosis and has been recorded graphically by most workers. The vibrations of an opening snap are of high frequency but sometimes of low intensity and it seems improbable that such phonocardiographs as are unable to record the faint basal diastolic murmurs should record these vibrations. In the present study the vibrations of an opening snap were present in 42 cases although an opening snap was only audible on auscultation in six.

The first reason why such vibrations might not be audible is that when the second heart sound is loud it may tire the human hearing mechanism and this would cause failure to hear a sound of low intensity occurring as it does within an interval of 0.1 seconds. Secondly, a loud systolic murmur that may mask the second heart sound could exert a similar effect. Finally, the opening vibrations may be mistaken for the second heart sound in such circumstances, unless the procedure described by Levine and Harvey (1949) of " inching" from base to apex is practised. The reason why so few opening snaps were heard in the present series is, however, that clear-cut cases of mitral stenosis constituted a very small percentage of the series. 
Classification by Combination of First Sound and Opening SNaP

The late onset of the first sound and the presence of vibrations at the time of A-V opening are both in all probability manifestations of organic disease of the mitral valve. It is not surprising, therefore, that their incidence is closely associated. The importance of this association has determined the grouping of the present series into the four groups.

Group 1. Normal 1st sound, opening snap absent. 48 cases.

Group 2. Late 1st sound, opening snap present. 41 cases.

Group 3. Late 1st sound, opening snap absent. 10 cases.

Group 4. Normal 1st sound, opening snap present. 1 case.
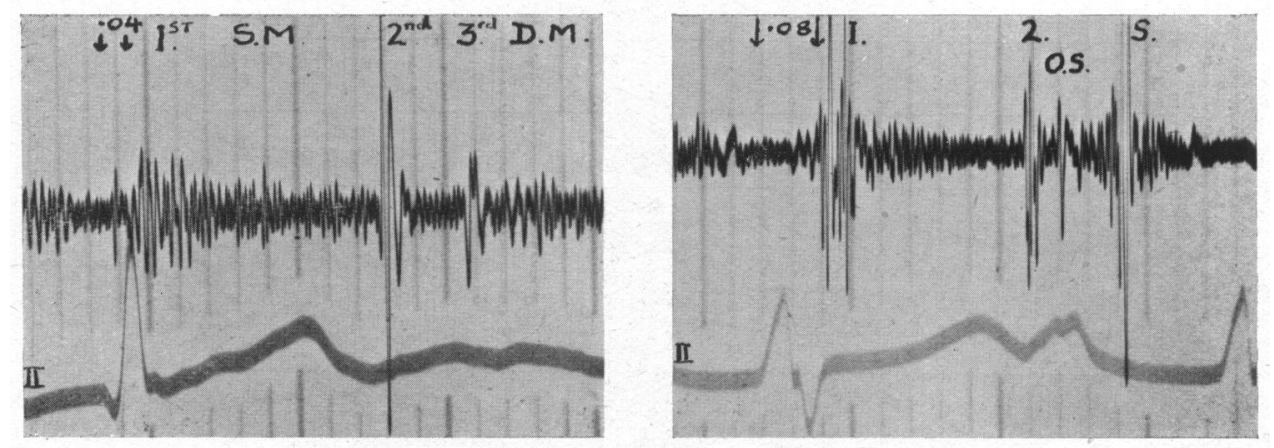

FIG. 8.-On the left there is a normal first sound and no opening snap. On the right there is a late first sound and opening snap. Neither of these features was audible on auscultation.

Fig. 8 shows examples from Groups 1 and 2 despite the fact that the findings on auscultation in these two patients were similar. Indeed, if the abnormality of the first sound and the presence of an opening snap on auscultation were used for a similar classification there would only be 6 patients in the second group and 21 in the third, while the remaining 73 would be in the first group.

The sub-division of cases into four groups has been used in presenting some features of the series. Table I gives the age of the patients and shows that most of the children under ten fell into the first group. It also shows the clinical diagnosis of the patients. There are only five in the second group whose clinical diagnesis was not rheumatic heart disease. The nature of the tracings suggests, nevertheless, the presence of mitral stenosis, and the follow-up of these patients will be interesting. Only one has died and she had been classified as congenital heart disease. Autopsy revealed mitral stenosis in addition to the other defects and the case is mentioned below (Fig. 11). Table II shows the relationship between the four groups and the auscultatory findings. This shows that four cases belong to Group 2 despite the absence of a diastolic murmur on auscultation. The presence of a late first sound and opening snap on the tracings nevertheless suggests the presence of mitral stenosis.

A systolic murmur was present in most of the patients in this study. It was sometimes conducted from a basal murmur of aortic stenosis or of a congenital malformation. At other times it was attributed to mitral regurgitation. Clinical experience suggests some relationship between the loudness of the systolic murmur of mitral regurgitation and the diastolic murmur of mitral stenosis. White (1944) states that " the louder one of these murmurs the less intense the other and if either murmur is marked the other is usually absent." Table III shows the phonocardiographic findings in this group. A standard sound source of constant intensity (500 cycles per second at 80 decibels above the threshold of audibility) was used to measure the intensity of the vibrations. This was not available during the latter part of the study and the assessment of intensities was then less accurate. The only constant impression from this analysis was that in the presence of sinus rhythm with a presystolic murmur systole was always relatively silent. 
TABLE I

Age Groups and Clinical Diagnosis of Patients Classified by Combination of First Sound and Opening Snap

\begin{tabular}{|c|c|c|c|c|c|c|c|c|c|c|}
\hline Age & \multicolumn{2}{|c|}{ Group 1} & \multicolumn{2}{|c|}{ Group 2} & \multicolumn{2}{|c|}{ Group 3} & \multicolumn{2}{|c|}{ Group 4} & \multicolumn{2}{|c|}{ Total } \\
\hline $\begin{array}{c}\text { Under } 10 \\
11-20 \\
21-30 \\
31-40 \\
41-50 \\
51-60 \\
\text { Over } 61\end{array}$ & & $\begin{array}{l}1 \\
0 \\
5 \\
2 \\
5 \\
2 \\
3\end{array}$ & & $\begin{array}{l}3 \\
0 \\
1 \\
9 \\
2 \\
2 \\
5 \\
1\end{array}$ & & $\begin{array}{l}1 \\
3 \\
1 \\
2 \\
2 \\
1 \\
1 \\
1\end{array}$ & & $\begin{array}{l}0 \\
1 \\
0 \\
0 \\
0 \\
0 \\
0\end{array}$ & & $\begin{array}{l}5 \\
4 \\
7 \\
3 \\
8 \\
8 \\
8 \\
5\end{array}$ \\
\hline Total & & 48 & & 11 & & 10 & & 1 & & \\
\hline \multicolumn{2}{|c|}{ Diagnosis } & \multicolumn{2}{|c|}{ Group 1} & \multicolumn{2}{|c|}{ Group 2} & \multicolumn{2}{|c|}{ Group 3} & \multicolumn{2}{|c|}{ Group 4} & \\
\hline \multicolumn{2}{|c|}{$\begin{array}{l}\text { Mitral stenosis } \\
\text { Rheumatic } \\
\text { Congenital } \\
\text { Syphilitic } \\
\text { Other conditions }\end{array}$} & \multicolumn{2}{|c|}{$\begin{array}{r}26 \\
5 \\
8 \\
2 \\
7\end{array}$} & \multicolumn{2}{|c|}{$\begin{array}{r}36 \\
0 \\
2 \\
1 \\
2\end{array}$} & & & $\begin{array}{l}73 \% \\
27 \%\end{array}$ \\
\hline
\end{tabular}

TABLE II

Auscultatory Findings in Relation to First Sound AND OPENING SNAP

\begin{tabular}{|c|c|c|c|c|}
\hline $\begin{array}{l}\text { Diastolic murmur } \\
\text { on auscultation }\end{array}$ & Group & $\begin{array}{l}\text { Group } \\
2\end{array}$ & $\underset{3}{\text { Group }}$ & $\underset{4}{\text { Group }}$ \\
\hline $\begin{array}{lll}\text { Definite } & . . & \ldots \\
\text { Questionable } & . . & \ldots \\
\text { Absent } & . . & \ldots\end{array}$ & $\begin{array}{r}32 \\
9 \\
7\end{array}$ & $\begin{array}{r}37 \\
2 \\
2\end{array}$ & $\begin{array}{l}8 \\
2 \\
0\end{array}$ & $\begin{array}{l}0 \\
1 \\
0\end{array}$ \\
\hline
\end{tabular}

TABLE III

Phonocardiographic Findings in Relation to Rhythm

\begin{tabular}{|c|c|c|c|c|c|c|}
\hline Rhythm & $\begin{array}{c}\text { Systolic } \\
\text { vibrations }\end{array}$ & $\underset{1}{\text { Group }}$ & $\underset{2}{\text { Group }}$ & $\underset{3}{\text { Group }}$ & $\underset{4}{\text { Group }}$ & Total \\
\hline Sinus rhythm with presystolic vibrations & $\begin{array}{l}\text { Slight } \\
\text { Intense }\end{array}$ & $\begin{array}{r}15 \\
5\end{array}$ & $\begin{array}{r}11 \\
0\end{array}$ & $\begin{array}{l}2 \\
\mathbf{0}\end{array}$ & $\begin{array}{l}1 \\
0\end{array}$ & $\begin{array}{r}29 \\
5\end{array}$ \\
\hline $\begin{array}{cccc}\text { Sinus rhythm without presystolic vibra- } \\
\text { tions } & . . & . & .\end{array}$ & $\begin{array}{l}\text { Slight } \\
\text { Intense }\end{array}$ & $\begin{array}{r}15 \\
6\end{array}$ & $\begin{array}{l}4 \\
8\end{array}$ & $\begin{array}{l}4 \\
0\end{array}$ & $\begin{array}{l}\mathbf{0} \\
\mathbf{0}\end{array}$ & $\begin{array}{l}23 \\
14\end{array}$ \\
\hline Auricular fibrilation, etc. .. & $\begin{array}{l}\text { Slight } \\
\text { Intense }\end{array}$ & $\begin{array}{l}5 \\
2\end{array}$ & $\begin{array}{r}7 \\
11\end{array}$ & $\begin{array}{l}3 \\
1\end{array}$ & $\begin{array}{l}\mathbf{0} \\
\mathbf{0}\end{array}$ & $\begin{array}{l}15 \\
14\end{array}$ \\
\hline
\end{tabular}

\section{Discussion}

The value of phonocardiography in the diagnosis of heart disease will only be established when there has been a careful correlation with operative or necropsy findings. One of the steps towards this is the demonstration that certain patterns exist on graphic records which suggest the presence of certain pathological conditions. The phonocardiographic classification on the basis of the late first sound and opening snap is very different from any possible classification on auscultatory find- 
ings alone. It is suggested that such a combination indicates the presence of mitral stenosis and that the absence of such features indicates merely left ventricular dilatation. This postulate is supported by a few autopsy findings.

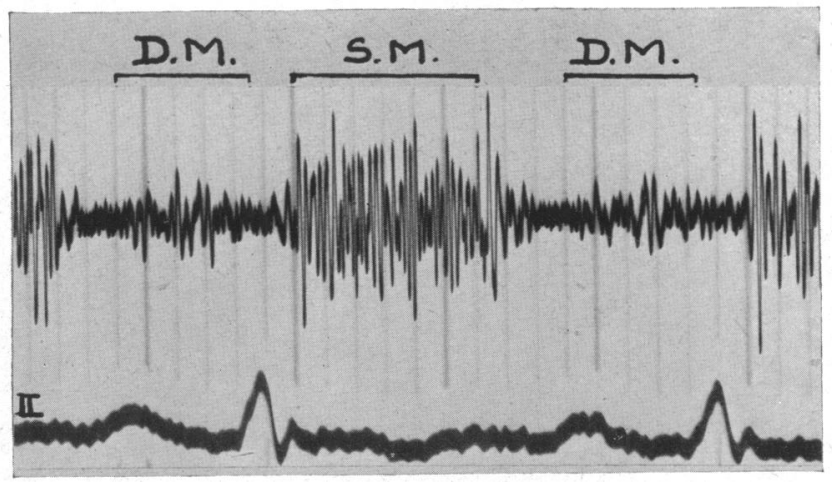

FIG. 9.-Systolic and diastolic murmurs in left ventricular dilatation (mitral valve normal at autopsy).

Case 1. A man; aged 48, with cardiac enlargement and congestive failure had a somewhat variable diastolic rumble at the apex. The tracings (Fig. 9) showed that the first heart sound was absent rather than delayed and there was no opening snap. Necropsy revealed a normal mitral valve with marked left ventricular dilatation.

Case 2. A man, aged 37, was diagnosed thirty years previously as having rheumatic heart disease. An apical diastolic murmur during the present admission was considered evidence of mitral stenosis. The phonocardiogram (Fig. 10) showed slight apical diastolic vibrations with presystolic accentuation. The first heart sound was not late and there was no opening snap. Necropsy revealed an extremely large patent ductus arteriosus with normal mitral valve and left ventricular dilatation.

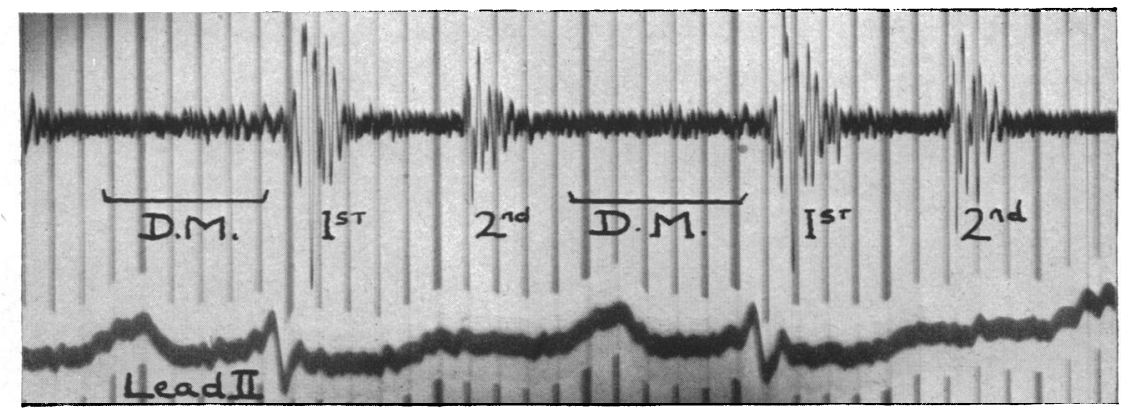

FIG. 10.-Diastolic and presystolic murmurs in patent ductus arteriosus (mitral valve normal at autopsy).

Case 3. A woman, aged 22, with cyanotic congenital heart disease had a presystolic murmur. The tracing (Fig. 11) showed the first heart sound was late and there was an opening snap. Necropsy revealed rheumatic mitral stenosis in addition to the tetralogy of Fallot.

The study of the various patterns of tracings with diastolic vibrations enables better understanding of those cases in which no diastolic murmur was present on auscultation. Auscultation had revealed no abnormality of the first sound and no diastolic murmur in one patient with congestive heart failure. The phonocardiogram, however, showed a late first sound, an opening snap, and vibrations in diastole like those of a diastolic murmur. This, patient was therefore believed to 
have mitral stenosis. In another patient there were significant diastolic vibrations on the phonocardiogram without audible murmur. Because of a normal first sound and no opening snap the tracing was considered to indicate left ventricular dilatation.

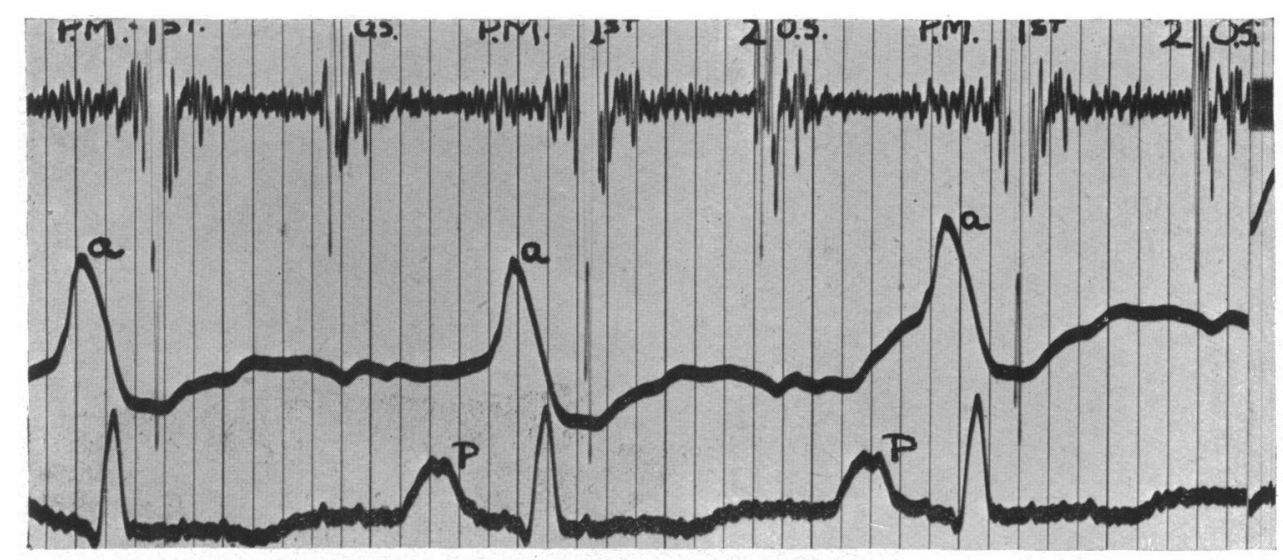

Fig. 11.-Abnormal first sound and "opening snap" in Fallot's tetralogy (autopsy revealed mitral stenosis in addition to other abnormalities).

\section{SUMMARY}

Recent technique and apparatus has enabled the faint diastolic murmur of aortic regurgitation to be consistently recorded for the first time. The same technique has been applied here to investigate in particular the high frequency components of tracings of apical diastolic murmurs.

One hundred tracings showing significant apical diastolic vibrations were analysed and the configuration of the vibrations described. Nearly half of the tracings showed both an abnormal delay in the onset of the maximal vibrations of the first sound and a series of high frequency vibrations at the time of A-V openings. It is considered probable that the occurrence of these two features indicates mitral stenosis although there is usually no auscultatory evidence of their presence. When diastolic vibrations occur without a late first sound and without an opening snap it seems probable that there is no mitral stenosis.

The validity of these postulates is unproven and awaits further confirmation by necropsy.

\section{REFERENCES}

Alimurung, M. M., Rappaport, M. B., and Sprague, H. B. (1949). New England J. Med., 241, 631.

Cossio, P., and Berconsky, I. (1943). Rev. Argent. de Cardiol., 10, 162.

-Levine, S. A., and Harvey, W. P. (1949). Clinical Auscultation of the Heart. W. B. Saunders.

Rappaport, M. B., and Sprague, H. B. (1941). Amer. Heart J., 21, 257.

- -, (1942). Amer. Heart J., 23, 591.

- The Standardisation of the Intensity of Heart Sounds and Murmurs. In preparation.

Wells, B. G., Rappaport, M. B., and Sprague, H. B. (1949). Amer. Heart J., 37, 586.

White, P. D. (1944). Heart Disease. Macmillan Co. 